\title{
Magnetic Equipped Wire Device-for Closed Interlocking Intramedullary Femoral Nailing: A Method That Avoids Exposure to Ionizing Radiations
}

\author{
Mohammad Hosein Ebrahimzadeh ${ }^{1}$; Hamid Farzadfar ${ }^{1}$; Hami Ashraf ${ }^{2}$; Gholam Reza \\ Khoshsima ${ }^{1}$; Ali Birjandinejad ${ }^{1,}$ \\ ${ }^{1}$ Orthopedic Research Center, Department of Orthopedic Surgery, Mashhad University of Medical Sciences, Mashhad, IR Iran \\ ${ }^{2}$ Department of Research and Education, Razavi Hospital, Mashhad, IR Iran \\ *Corresponding author: Ali Birjandinejad, Orthopedic and Trauma Research Center, Department of Orthopedic Surgery, Mashhad University of Medical Sciences, Mashhad, IR Iran. \\ Tel:+98-5138523300, Fax:+98-5138549234, E-mail: birjandinejadA@mums.ac.ir
}

Received: July 28, 2014; Revised: August 4, 2014; Accepted: August 4, 2014

\begin{abstract}
Background:Intramedullary nailing is probably the best procedure for treating the long bone fractures in the lower limb.Such operation is guided by fluoroscopy for the guide-wire insertion like fracture reduction and distal locking. Radiation exposure during interlocked nailing continues a matter of challenge.

Objectives: The aim of this experimental study was to design and test the new aiming device for closed intramedullary nailing and to reduce the radiation exposure and the operation time during the procedure.

Materials and Methods: A stainless steel femoral intramedullary guide wire equipped with a small magnet on its end was designed; and also an exchange tube that would enter into the bone canal upon the guide wire to maintain the alignment. Besides these mentioned parts, we applied the standard classic interamedullary nailing set. Pin guide was inserted in the femoral intramedullary canal from periformis fossa. Another equipped magnetic guide wire was inserted from distal portal which was created in the lateral epicondyle. Two opposite magnetic poles supposed to find each other in the fracture site. After replacing the guide-wire with guide pine; the alignment would be checked by a C-arm. The study has been designed in 4 phases including moulage phase, animal phase on young cows, and a human cadaveric phase. The last step of the study is under design and it consists of a randomized controlled clinical trial on the elective patients. Results: Outcomes of applying the new system on 15 fiberglass artificial femurs and 20 bovine femurs as well as 10 human cadaveric femurs were successful.

Conclusions: We found the magnetic field assistant device to be an accurate, radiation-independent jig for close passing of guide wire after close reduction of femoral fracture. It can reduce the need for radiation during placement of guide wire for closed intramedullary nailing of the long bones. More studies are required to improve and evaluate the technique and equipment.
\end{abstract}

Keywords:Intramedullary Nailing; Bone Fracture; Radiation; Magnet; Magnetic

\section{Background}

Fractures involving the shaft of long bones are common worldwide. Femur is the largest, longest and the strongest bone in the human skeleton. Fractures of the shaft of the femur could be the result of high energy or low energy trauma; about one of three patients' fractures is caused by multiple injuries (1). The methods used to achieve skeletal stabilization could be various considerably, depending on the configuration of the fracture line and the geographical location of the surgeons' practices (2). Interests for minimally invasive surgery have led to increased number of procedures being done percutaneously $(3,4)$. Closed intrameduulary nailing is guided by fluoroscopy for guide-wire insertion, closed reduction, and distal locking. Radiation exposure during closed intramedullary nailing is a challenging concern for surgeon and operating room personnel (5-8). Mehlman and Dipasquale (9) proved that operating room personnel within 24 inches from the fluoroscopy beam (like free- hand technique for interlocking screw insertion by a radiolucent drill) received significant amounts of radiation exposure, especially to the insecure eyes, neck, and hands (10). Muller et al. (10) measured the radiation exposure to the hands of the surgeon during 41 procedures of intramedullary nailing of femoral and tibial fractures. Surgeons and their assistant wore ring dosimeters on their dominant index fingers. The average fluoroscopy exposure time was $4.6 \mathrm{~min}$ per procedure. Besides the average dose of radiation to the dominant hand of the primary surgeon was 1.27 and $1.19 \mathrm{mSv}$ to the first assistant (10). The maximum permissible dose (MPD) for the whole body, head, neck, trunk, eyes, bone marrow and gonads, that was recommended by the International Commission on Radiological Protection (ICRP) is $50 \mathrm{mSv}$ per year. Besides the MPD for the extremities, hands and feet is 500 $\mathrm{mSv}$ per year. A lead apron provides adequate protection for the trunk and gonads of the surgeon, while the hands

Copyright (c) 2014, Razavi Hospital. This is an open-access article distributed under the terms of the Creative Commons Attribution License, which permits unrestricted use, distribution, and reproduction in any medium, provided the original work is properly cited. 
are exposed to scatter radiation $(11,12)$. The hypothesis for the current study was that this magnet equipped guide wire can reduce the need for x-ray exposure for closed intramedullary nailing. This device allows simple and accurate insertion of reduction guide-wire with minimum radiation exposure to the patients and the surgeons. It also decreased the operation time.

\section{Objectives}

The aim of this experiment was to design and evaluate the new tool to eliminate the radiation exposure and reduce the operation time during the procedure.

\section{Materials and Methods}

The present descriptive study was approved by the research committee of our institute. We have designed a magnetic-assistant device that included the following set;

1) A stainless style guide-wire with $3 \mathrm{~mm}$ diameter, and $1.5 \mathrm{~mm}$ length. It could be equipped at the end with different magnets in size and type, which was selected according to the patients' bone canal size.

2) A plastic or metal exchange tube that would enter into the bone canal upon the guide wire to maintain the alignment. By inserting a guide pin into the bone canal, reaming of the distal and proximal parts would be continued as a standard classic procedure.

3) Besides these mentioned parts, we applied the standard classic interamedullary nailing set.

\subsection{Study Design}

This study was designed in four phases. First, a moulage phase on 15 fiberglass synthetic bones. At the second step, we used 20 young cows' femoral bone, which were fractured in the mid-shaft. For the next part of this study, 10 human cadavers were considered with femoral bones mid-shaft fracture. A pin guide which was equipped with a $3^{*} 3 \mathrm{~mm}$ powerful magnet at the tip was inserted in the femoral intramedullary canal from periformis fossa. Another portal was created in the lateral epicondyle of femur and the second equipped magnetic guide wire was inserted from this distal poral. Two opposite magnetic poles supposed to find each other in the fracture site with a small range of manipulation (Figure $1 \mathrm{a}$ and $\mathrm{b}$ ).

A standard exchange tube is used to magnetic guide wire, and the guide-wire replaced with guide pine for its reaming and then a magnetic equipped wire is removed. The alignment would be checked by a C-arm traditional method. This surgical set was registered in Iranian patent registry. The human phase of this study is under review and it consists of a randomized controlled clinical trial on the patients with mid-shaft femoral fractures after approval of Ethic Committee in Human Researches of our institution, Mashhad University of Medical Sciences.

\section{Results}

The results of applying the new system on 15 fiberglass
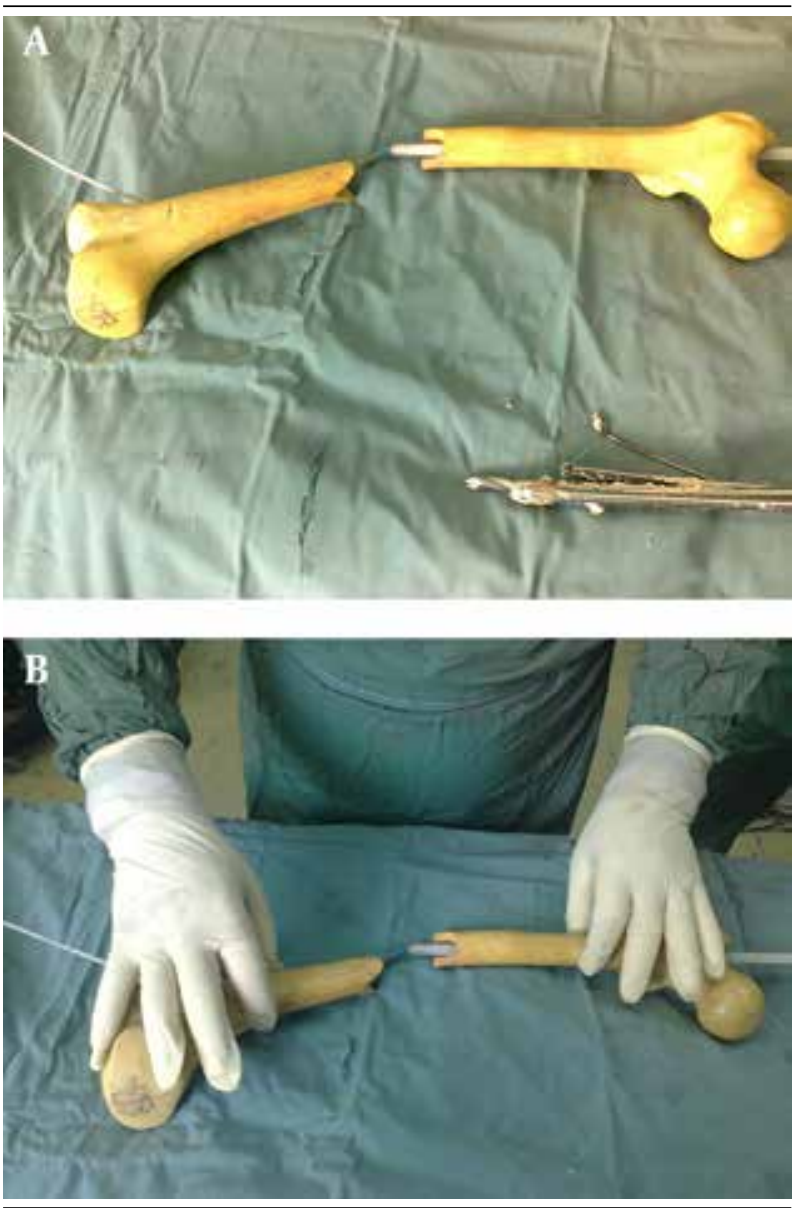

Figure 1. Two Opposite Magnetic Poles Are Finding Each Other on the Molage Bone

artificial femurs and 20 bovine femurs as well as $10 \mathrm{hu}-$ man cadaveric femurs were presented successfully. The first phase was in moulage. It really helped as a theory to practice for the next steps. In the second phase, we administered the device in 20 cows with closed femoral bone fractures and we had little problem to find both ends of magnet equipped wire device. But the most difficult phase was in bovine bones in which reaming the big bones was really hard. Finding the alignment was a little difficult in cadaveric bones, because tissue stiffness manipulation required for magnets to fine each other was not as simple as live tissues. In this step, we operated 10 fractured cadaveric femoral bones with our magnetic set successfully. Instillation of C-arm was limited to final check in this group. On the other hand, operation of the 10 cadavers under the guide of fluoroscopy led to just 10 shots of C-Arm. No deviation from expected results was seen. We could create and maintain the alignment of fractured bones without applying the ionizing radiation.

\section{Discussion}

The exclusion of an image intensifier eliminates automatically the harmful effect of an increased dose of radiation for both the surgery team and the patient $(2,4-20)$. 
It does not cost the patient a lot, and also it ensures highquality fracture care comparable to any developed countries (2). Intramedullary nail insertion can be performed with minimal fluoroscopic control for fracture reduction and intramedullary reaming. Proximal interlocking screw placement can also be reliably performed by using a proximal targeting device and minimal fluoroscopy $(13,14,21)$. However, one of the most difficult chores in intramedullary nailing insertion is closed passing of the guide wire for reduction at the fracture ends, especially when some days have left from the fracture, in the shortest time, and the least possible exposure to radiation. A variety of aiming tools that would limit the need of fluoroscopy for the correct insertion of the distal interlocking screws have been proposed. Anastopoulos and colleagues expressed that radiation exposure during distal locking was 36 seconds (19.08 minutes of surgical time for distal locking and 81 seconds of total fluoroscopy time) for the freehand technique contrast of 15 seconds (17.06 minutes of surgical time during distal locking and 69 seconds of total fluoroscopy time) for the Orthofix® targeting device (three distal screws) (20). Levin et al. (17) reported 2.7 minutes of fluoroscopy time that was ranged between 0.6-6.6 minutes with 12 mrem mean of radiation exposure for distal locking of tibial nails. Recent studies have reported that the mean fluoroscopy time was 3.44 minutes in Sanders et al. (19), and $137 \pm 111 \mathrm{mGy}$ and $5.7 \pm 3.5$ minutes of radiation exposure for tibial fracture nailing in Tsalafoutas et al. (22). Anastopoulos et al. required two exposures of 0.85 seconds that was ranged from 0.4 to 1.2 seconds and 1.4 mGy was ranged from 0.8 to $1.9 \mathrm{mGy}$ for all cases (20). Orthofix@ has developed a distal targeting device which compensates for the inevitable deformation of the nail in the sagittal plane during insertion for restriction the usage of fluoroscopy during distal interlocking screw placement. Babis et al. (23) has reported the usage of Orthofix® distal targeting device on 230 distal locking during 8 years study. They were not succeeded in inserting the distal locking screws at the first attempt without using the image intensifier $12(5.2 \%)$ cases. They concluded that failure might be attributed to two reasons; first they are not adequate experienced in the initial learning curve period (24) and second there was not proper handling for the distal targeting device (23). Radiation exposure for classic intramedullary nailing of the femur and tibia is decreased due to the innovation of different targeting device for distal locking and continues experience of new orthopedic trauma surgeons. Our novel magnet equipped wire device system during reduction and guide wire passage is planned to make closed intramdullary reduction and nailing without exposure to $\mathrm{X}$-ray. Regarding the different difficulties, our novel designed device could successfully perform all the nailing steps independent of an image intensifier in addition to reducing the expenses for the patients. We found the Magnet Equipped Wire Devices an accurate, radiation- independent jig. With this new method of interlocking intramedullary nail, passing the wire and reduction of the fracture by the magnetic wire device, the need for radiation could be eliminated or decreased. These primary results should stimulate the further clinical application of this device.

\section{Acknowledgements}

The authors thank the Vice Chancellor for Research of Mashhad University of Medical Sciences for technical supports. Authors also know it necessary to appreciate Mrs Najmeh Jafari Moghadam for her helps in preparing and submitting the manuscript.

\section{Authors' Contributions}

Study concept and design: Farzadfar, Ebrahimzadeh, Birjandinejad and Ashraf; analysis and interpretation of data: Farzadfar, Taraz Jamshidi, and Ebrahimzadeh; drafting of the manuscript: Birjandinejad, Farzadfar, and Ebrahimzadeh; critical revision of the manuscript for important intellectual content: Ebrahimzadeh, Ashraf, Birjandinejad and Taraz Jamshidi. The authors declare that they have no conflict of interest. All the authors have checked and approved the last version of the manuscript.

\section{Funding/Support}

This study was observed by Vice Chancellor of Research, Mashhad University of Medical Sciences without any grant.

\section{References}

1. Logters T, Windolf J, Flohe S. [Fractures of the shaft of the femur]. Unfallchirurg. 2009;112(7):635-50.

2. Ikem IC, Ogunlusi JD, Ine HR. Achieving interlocking nails without using an image intensifier. Int Orthop. 2007;31(4):487-90.

3. Hooper GJ, Keddell RG, Penny ID. Conservative management or closed nailing for tibial shaft fractures. A randomised prospective trial. J Bone Joint Surg Br. 1991;73(1):83-5.

4. Fadero PE, Alabi S, Adebule GT, Odunubi OO, Yinusa W, Eyesan SU, et al. Locked intramedullary nailing for the treatment of femoral shaft fractures: experience and result in 19 cases. Niger J Med. 2008;17(2):168-72.

5. Barry TP. Radiation exposure to an orthopedic surgeon. Clin Orthop Relat Res.1984(182):160-4.

6. Dosch JC, Dupuis M, Beck G. [Radiation measurements during interlocking nailing]. Hefte Unfallheilkd.1983;161:36-8.

7. Krettek C, Mannss J, Konemann B, Miclau T, Schandelmaier P, Tscherne $\mathrm{H}$. The deformation of small diameter solid tibial nails with unreamed intramedullary insertion. J Biomech. 1997;30(4):391-4.

8. Krettek C, Schandelmaier P, Tscherne H. Nonreamed interlocking nailing of closed tibial fractures with severe soft tissue injury. Clin Orthop Relat Res.1995(315):34-47.

9. Mehlman CT, Dipasquale TG. Radiation exposure to the orthopaedic surgical team during fluoroscopy: "how far away is far enough?". J Orthop Trauma.1997;11(6):392-8.

10. Muller LP, Suffner J, Wenda K, Mohr W, Rommens PM. Radiation exposure to the hands and the thyroid of the surgeon during intramedullary nailing. Injury. 1998;29(6):461-8.

11. Madan S, Blakeway C. Radiation exposure to surgeon and patient in intramedullary nailing of the lower limb. Injury. 2002;33(8):723-7. 


\section{Ebrahimzadeh MH et al.}

12. Kirousis G, Delis H, Megas P, Lambiris E, Panayiotakis G. Dosimetry during intramedullary nailing of the tibia. Acta Orthop 2009;80(5):568-72.

13. Whatling GM, Nokes LD. Literature review of current techniques for the insertion of distal screws into intramedullary locking nails. Injury. 2006;37(2):109-19.

14. Gugala Z, Nana A, Lindsey RW. Tibial intramedullary nail distal interlocking screw placement: comparison of the free-hand versus distally-based targeting device techniques. Injury. 2001;32 Suppl 4:SD21-5.

15. Kelley SS, Bonar S, Hussamy OD, Morrison JA. A simple technique for insertion of distal screws into interlocking nails. J Orthop Trauma.1995;9(3):227-30.

16. Krettek C, Konemann B, Miclau T, Kolbli R, Machreich T, Kromm A, et al. A new mechanical aiming device for the placement of distal interlocking screws in femoral nails. Arch Orthop Trauma Surg. 1998;117(3):147-52.

17. Levin PE, Schoen RW, Jr, Browner BD. Radiation exposure to the surgeon during closed interlocking intramedullary nailing. $J$ Bone Joint Surg Am.1987;69(5):761-6.

18. Miller ME, Davis ML, MacClean CR, Davis JG, Smith BL, Humphries JR. Radiation exposure and associated risks to operating-room personnel during use of fluoroscopic guidance for selected orthopaedic surgical procedures. JBone Joint Surg Am.1983;65(1):1-4

19. Sanders R, Koval KJ, DiPasquale T, Schmelling G, Stenzler S, Ross E. Exposure of the orthopaedic surgeon to radiation. J Bone Joint Surg Am. 1993;75(3):326-30.

20. Anastopoulos G, Ntagiopoulos PG, Chissas D, Papaeliou A, Asimakopoulos A. Distal locking of tibial nails : a new device to reduce radiation exposure. Clin Orthop Relat Res. 2008;466(1):216-20.

21. Abdlslam KM, Bonnaire F. Experimental model for a new distal locking aiming device for solid intramedullary tibia nails. Injury. 2003;34(5):363-6.

22. Tsalafoutas IA, Tsapaki V, Kaliakmanis A, Pneumaticos S, Tsoronis F, Koulentianos ED, et al. Estimation of radiation doses to patients and surgeons from various fluoroscopically guided orthopaedic surgeries. Radiat Prot Dosimetry. 2008;128(1):112-9.

23. Babis GC, Benetos IS, Zoubos AB, Soucacos PN. The effectiveness of the external distal aiming device in intramedullary fixation of tibial shaft fractures. Arch Orthop Trauma Surg. 2007;127(10):905-8.

24. Karachalios T, Babis G, Tsarouchas J, Sapkas G, Pantazopoulos T. The clinical performance of a small diameter tibial nailing system with a mechanical distal aiming device. Injury. 2000;31(6):451-9. 